\title{
Dynamic response of Antarctic ice shelves to bedrock uncertainty
}

\author{
S. Sun ${ }^{1}$, S. L. Cornford ${ }^{2}$, Y. Liu ${ }^{1}$, and J. C. Moore ${ }^{1,3,4}$ \\ ${ }^{1}$ College of Global Change and Earth System Science, Beijing Normal University, Beijing, China \\ ${ }^{2}$ School of Geographical Sciences, University of Bristol, Bristol BS8 1SS, UK \\ ${ }^{3}$ Arctic Centre, University of Lapland, PL122, 96100 Rovaniemi, Finland \\ ${ }^{4}$ Department of Earth Sciences, Uppsala University, Villavägen 16, Uppsala, 75236, Sweden
}

Correspondence to: J. C. Moore (john.moore.bnu@gmail.com)

Received: 2 January 2014 - Published in The Cryosphere Discuss.: 21 January 2014

Revised: 27 June 2014 - Accepted: 1 July 2014 - Published: 21 August 2014

\begin{abstract}
Accurate and extensive bedrock geometry data is essential in ice sheet modelling. The shape of the bedrock on fine scales can influence ice sheet evolution, for example through the formation of pinning points that alter grounding line dynamics. Here we test the sensitivity of the BISICLES adaptive mesh ice sheet model to small-amplitude height fluctuations on different spatial scales in the bedrock topography provided by Bedmap2 in the catchments of Pine Island Glacier, the Amery Ice shelf and a region of East Antarctica including the Aurora Basin, Law Dome and Totten Glacier. We generate an ensemble of bedrock topographies by adding random noise to the Bedmap2 data with amplitude determined by the accompanying estimates of bedrock uncertainty. We find that the small-amplitude fluctuations result in only minor changes in the way these glaciers evolve. However, lower-frequency noise, with a broad spatial scale (over tens of kilometres) is more important than higher-frequency noise even when the features have the same height amplitudes and the total noise power is maintained. This is cause for optimism regarding credible sea level rise estimates with presently achievable density of thickness measurements. Pine Island Glacier and the region around Totten Glacier and Law Dome undergo substantial retreat and appear to be more sensitive to errors in bed topography than the Amery Ice shelf region which remains stable under the present-day observational data uncertainty.
\end{abstract}

\section{Introduction}

Future mass loss from Antarctica is the most significant unknown part of the global sea level budget (Moore et al., 2013). Almost all the snow that falls on Antarctica is carried by ice flow from the continent (Rignot et al., 2008, 2013). Ice shelves play an important role in the mass balance of the Antarctic ice sheet through their buttressing effect on the grounded ice sheet (Pritchard et al., 2012). Modification of back stress across the grounding line due to ice-shelfgrounded locations or embayments will hence impact sea level rise. Antarctica lost about $1420 \pm 1060 \mathrm{Gt}$ of grounded ice between 1992 and 2011 (Shepherd et al., 2012), equivalent to an increase in global mean sea level of $4.0 \pm 3.0 \mathrm{~mm}$.

Using high-precision remote-sensing observations (e.g. Wingham et al., 1998, 2006; Rignot and Thomas, 2002; Zwally et al., 2005; Velicogna and Wahr, 2006; Dutrieux et al., 2013; Sasgen et al., 2013), estimates of ice sheet mass balance can be made. For East Antarctica, the ice sheet is close to balance (Rignot et al., 2008; Shepherd and Wingham, 2007; Shepherd et al., 2012). However, regionally ice shelves differ, with net ice loss in some glaciers in Wilkes Land and gain in the Filchner and Ross ice shelves (Rignot et al., 2008). West Antarctica has long been known to be responsible for most of the negative Antarctic mass balance (Wingham et al., 2006). For example, Pine Island Glacier lost about $101.2 \pm 8 \mathrm{Gt} \mathrm{yr}^{-1}$ between the year 2003 and 2008 (Rignot et al., 2013).

Bedrock topography is an important parameter when simulating ice sheet evolution. Many Antarctic phenomena are tightly controlled by the bedrock topography, such as the surface undulation of ice streams (De Rydt et al., 2013), 
grounding line retreat (Favier et al., 2012) and tidewater outlet glaciers dynamics (Enderlin et al., 2013).

Regions of reverse-sloping bedrock in West Antarctica have been studied in some depth because of the possibility of marine ice sheet instability, where grounding line retreat into deeper topography tends to accelerate. Schoof (2007) shows that there are no stable grounding line positions on a bed sloping up toward the ocean in flow line geometries with free-floating ice shelves, but stable grounding line positions have been shown to occur in more complex threedimensional models (Gudmundsson et al., 2012). Favier et al. (2012) used a two-dimensional full Stokes model to show that pinning points beneath an ice shelf have a stabilizing effect on the ice dynamics (Favier et al., 2012), while Durand et al. (2011) examined the sensitivity of an ice sheet lying on a reverse bedrock slope to varying hill and trough geometry close to the grounding line.

Bedrock topography has been observed primarily by radar sounding in the megahertz frequency range (e.g. Robin et al., 1969), with bandwidths and hence vertical resolutions in the $10 \mathrm{~m}$ range. Seismic surveys have also been particularly useful on ice shelves (Pozdeev and Kurinin, 1987) where the presence of slightly saline marine ice layers may prevent penetration of radar waves (Moore et al., 1994) and sea water prevents mapping of the sub-shelf cavity. The amplitude of the ice thickness uncertainty in mapped topography will vary both along the radar flight line as a result of the bandwidth of the radar used and in between flight lines as a result of the mapping interpolation algorithms selected. The spacing between flight lines is seldom less than some kilometres and over much of Antarctica may be considerably larger (Fretwell et al., 2013). Besides the large-amplitude fluctuations, such as those produced by hills and valleys, the small-amplitude errors in elevation or irregularities in the bed may affect ice sheet evolution. For example, the differences in surface roughness or fractal dimension between a hard rock bed substrate and a fine sedimentary deposit will not be directly visible using radars presently designed to map ice sheet thickness. To date no research on the impact of these small-amplitude bedrock fluctuations on the modelling of real glaciers with three-dimensional topography has been made. However, Durand et al. (2011) used a two-dimensional full Stokes model on synthetic Pine-Island-like flow line geometry and found that, if the bedrock was undersampled, then a large bias of up to $25 \%$ in ice volume in the basin could occur. In ice sheet modelling, the data are necessarily interpolated from (relatively) sparse observations and often smoothed to allow representation in continuum models which require continuous spatial derivatives to exist. In reality, there will be small-amplitude fluctuations making the bedrock rougher. The density of ice thickness measurements determines the amplitude of the fluctuations that may exist in each location - and this has a standard deviation from $50 \mathrm{~m}$ to about $1 \mathrm{~km}$. We call these uncertainties noise and want to test the sensitivity of Antarctic ice sheet to this bedrock noise. We wish here to quantify various issues:

- Will the bedrock noise affect the evolution of the ice sheet, such as grounding line retreat and mass balance change, and how?

- How much can we trust our modelling result?

- Which kind of noise has larger influence on the glacier - lower frequency or higher frequency?

- Since the bedrock features are quite different between East and West Antarctica, how do their ice sheets respond to the same kind of noise?

To answer these questions, we carried out sensitivity experiments with bedrock noise on three basins: Pine Island Bay, the Lambert-Glacier-Amery-Ice-shelf system and the Aurora Basin (which includes Totten Glacier) (Fig. 1). Pine Island Glacier (PIG) is the archetype of a vulnerable West Antarctic glacier, lying on reverse sloping bedrock below the sea level (Fig. 2a) with its grounding line retreating rapidly at present. Most of the Lambert Basin is above sea level, with a deep trough, however, beneath the Amery Ice shelf (Fig. 2b). The mass balance of this system is estimated to be close to 0 but with large uncertainty. The bedrock of the Aurora Basin is flat and close to sea level with a deep trough beneath Totten Glacier (Fig. 2c), which occupies a northerly location close relatively warm waters (Rignot et al., 2013) and is thinning, in contrast to much of East Antarctica (Pritchard et al., 2012). We add noise of three different spectral frequencies to the bedrock maps of these glaciers and carry out a simulation of 200 years to make a noise sensitivity analysis.

In Sect. 2, we introduce the methodology of tuning the model and making the noisy bedrock input data. In Sect. 3, we show the results of the three different glacier outcomes responding to different frequency bedrock noise and discuss the results and implications in Sect. 4.

\section{Methods}

We chose to consider the effect of small-amplitude noise distributed according to Bedmap2 estimates of uncertainty in bedrock topography on real ice shelves using a threedimensional model. We created three varieties of red noise (that is, random noise whose power spectrum decays with frequency): high, medium and low frequency. To explore statistical variability, we use 50 different realizations of topography disturbed by initially white Gaussian noise transformed for each frequency range of noise.

\subsection{Producing noisy data}

Our model was initialized using the best available bedrock topography. For PIG, we simulate a $512 \times 512 \mathrm{~km}^{2}$ area, 


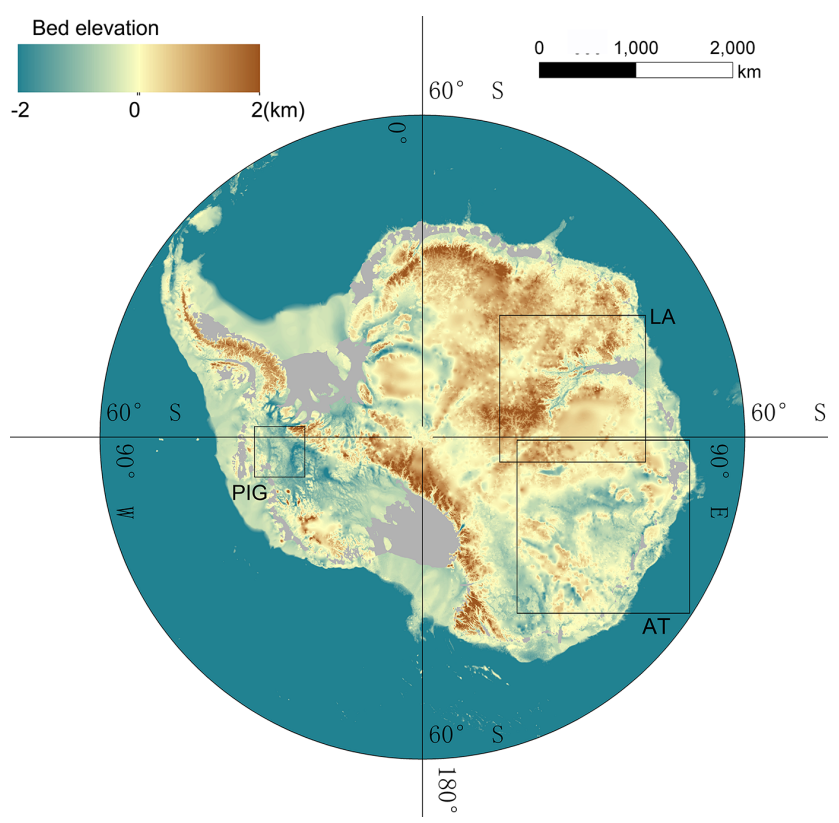

Figure 1. The three basins (boxed) we simulated on the Bedmap2 Antarctic bedrock topography map (Fretwell et al., 2013). Pine Island Glacier (PIG) is shown in Fig. 2a, Lambert-Amery (LA) system is shown in Fig. $2 b$ and the Aurora-Basin-Totten-Glacier region (AT) is shown in Fig. 2c.

using a $1 \mathrm{~km}$ resolution DEM (digital elevation map) constructed along the same lines as the $5 \mathrm{~km}$ ALBMAP DEM (Le Brocq et al., 2010), which differs by only tens of metres from the same region on Bedmap2 (Fretwell et al., 2013). For the Lambert-Glacier-Amery-Ice-shelf system $\left(1536 \times 1536 \mathrm{~km}^{2}\right.$ domain $)$ and Aurora-Basin-TottenGlacier region $\left(1792 \times 1792 \mathrm{~km}^{2}\right.$ domain $)$, we use the Bedmap2 geometry data (Fretwell et al., 2013).

First, we create two-dimensional white noise on the domain we modelled, named $f(x, y)$, where $x$ and $y$ are the domain coordinate. The PIG domain has 512 grid cells in both $x$ and $y$ directions, so the value ranges of $x$ and $y$ are both 1512. Since we want to test the ice sheet sensitivity to the frequency of bedrock noise, we have to create noise of high frequency and low frequency. We transform our noise $f(x, y)$ from the spatial domain to the frequency domain through the two-dimensional discrete Fourier transform. Assume the noise on the frequency domain is $F(u, v)$, then $f(x, y)$ and $F(u, v)$ are related by

$F(u, v)=\sum_{x=0}^{M-1} \sum_{y=0}^{N-1} f(x, y) e^{-i 2 \pi\left(\frac{u x}{M}+\frac{v y}{N}\right)}$,

where $0 \leq u \leq M-1,0 \leq v \leq N-1$.

$M$ and $N$ are the number of grid nodes in the $x$ and $y$ directions, and here for all three of our sites $M=N$. Then we rearrange the outputs by moving the zero-frequency component to the centre of the array. The Gaussian low pass filter has the following form:

$H(u, v)=e^{-\left[\left(u-\frac{M}{2}\right)^{2}+\left(v-\frac{N}{2}\right)^{2}\right] / 2 \sigma^{2}}$.

After filtering by the Gaussian low pass filter (in other words, by the function $F(u, v) \cdot H(u, v)$, the original white noise has been mapped to noise with a frequency distribution determined by the isotropic standard deviation $\sigma$. We chose $\sigma=10,50,100$ (units: $1 / M$ cycles $\mathrm{km}^{-1}$ ) to generate lower-, medium- and higher-frequency noise (Fig. 3). We then transform the noise back to the spatial domain as

$$
\begin{gathered}
f(x, y)=\operatorname{Re}\left(\frac{1}{M N} \sum_{u=0}^{M-1} \sum_{v=0}^{N-1} F(u, v)\right. \\
\left.\cdot H(u, v) e^{i 2 \pi\left(\frac{u x}{M}+\frac{v y}{N}\right)}\right) .
\end{gathered}
$$

When filtering the noise, we tune the power of the white noise to keep the lower-, medium- and higher-frequency noise at the same power. For PIG, which has the most dense coverage of radar, errors are more or less constant over the whole region and most of the noise values are in the range of -60 to $60 \mathrm{~m}$. Figure $3 \mathrm{e}-\mathrm{g}$ show the effects of the three noise distributions on the bedrock height noise patterns. Since the amplitude of variation is determined by the uncertainty in the observations, in reality the lowest-frequency pattern may mimic the effects of coherent bias in errors, producing broad features with gentle slopes on special scales of tens of kilometres (Fig. 3e). The medium- (Fig. 3f) and higher- (Fig. 3g) frequency noise patterns vary over smaller spatial scales and can represent moderately sloping surface undulations or rough terrain down to kilometre scales. For the two other regions we study, the bedrock mapping uncertainty varies spatially, and so the noise amplitudes are designed to vary spatially also, but we still can define the noise distributions in frequency space as for the PIG example in Fig. 3b-d.

For the East Antarctic Ice Sheet, the uncertainty of bedrock elevation data ranges from $66 \mathrm{~m}$ to more than $1000 \mathrm{~m}$, so we use different noise ranges according to the local data uncertainty (Fretwell et al., 2013). As is shown in Fig. $4 \mathrm{a}$ and c, there are topographic uncertainties with 16 different values across different domains. We combined closest values such as $151,152,154 \mathrm{~m}$ into a class where the uncertainties lie in the intervals $[66,100] \mathrm{m},[100,180] \mathrm{m},[180$, $238] \mathrm{m},[238,500] \mathrm{m}$ and $[500,1008] \mathrm{m}$. In each of these areas, we created maps of noise with the standard deviation of around $88,150,200,300$ and $1000 \mathrm{~m}$, and then we combined these noise sets to create a map spanning the model domain (Fig. $4 b$ and d).

After making the bedrock noise, we add it to the bedrock map beneath the grounded ice sheet and subtract the same value from ice sheet thickness to keep the surface elevation consistent with the geometry data. We also limit the change of thickness and topography at any grid point such that the grounding line is not altered.

To summarize, a Gaussian low pass filter is used to select noise with three different frequency distributions but with 

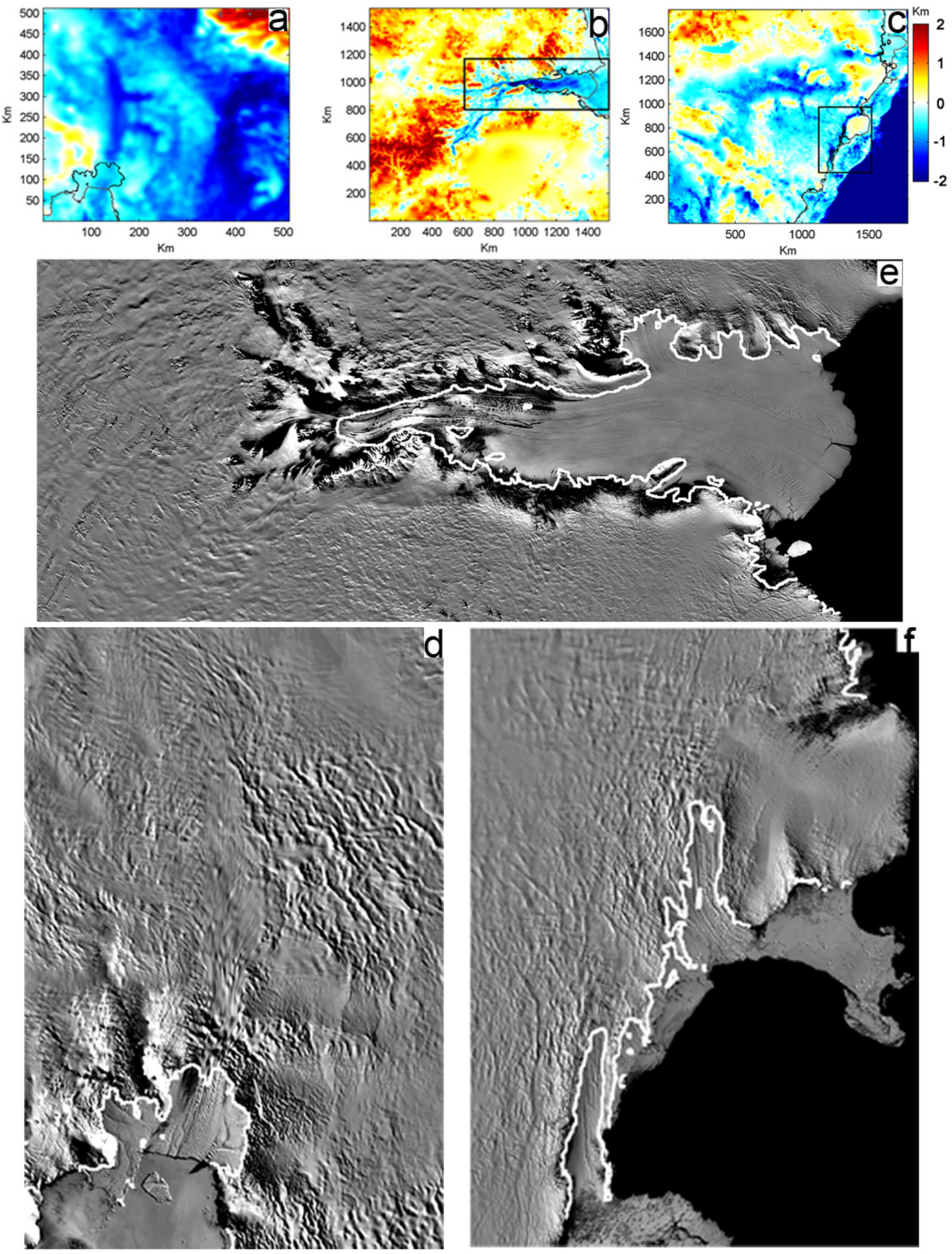

Figure 2. Bedrock topography map for PIG (a; Le Brocq, et al., 2010), LA (b; Fretwell et al., 2013) and AT (c; Fretwell et al., 2013). Grounding lines are shown in black. (d-f) are MODIS Mosaic of Antarctica (MOA) Image Map 2003-2004 images, (Scambos et al., 2007) of the boxed areas in (a-c) with grounding lines shown in white. 

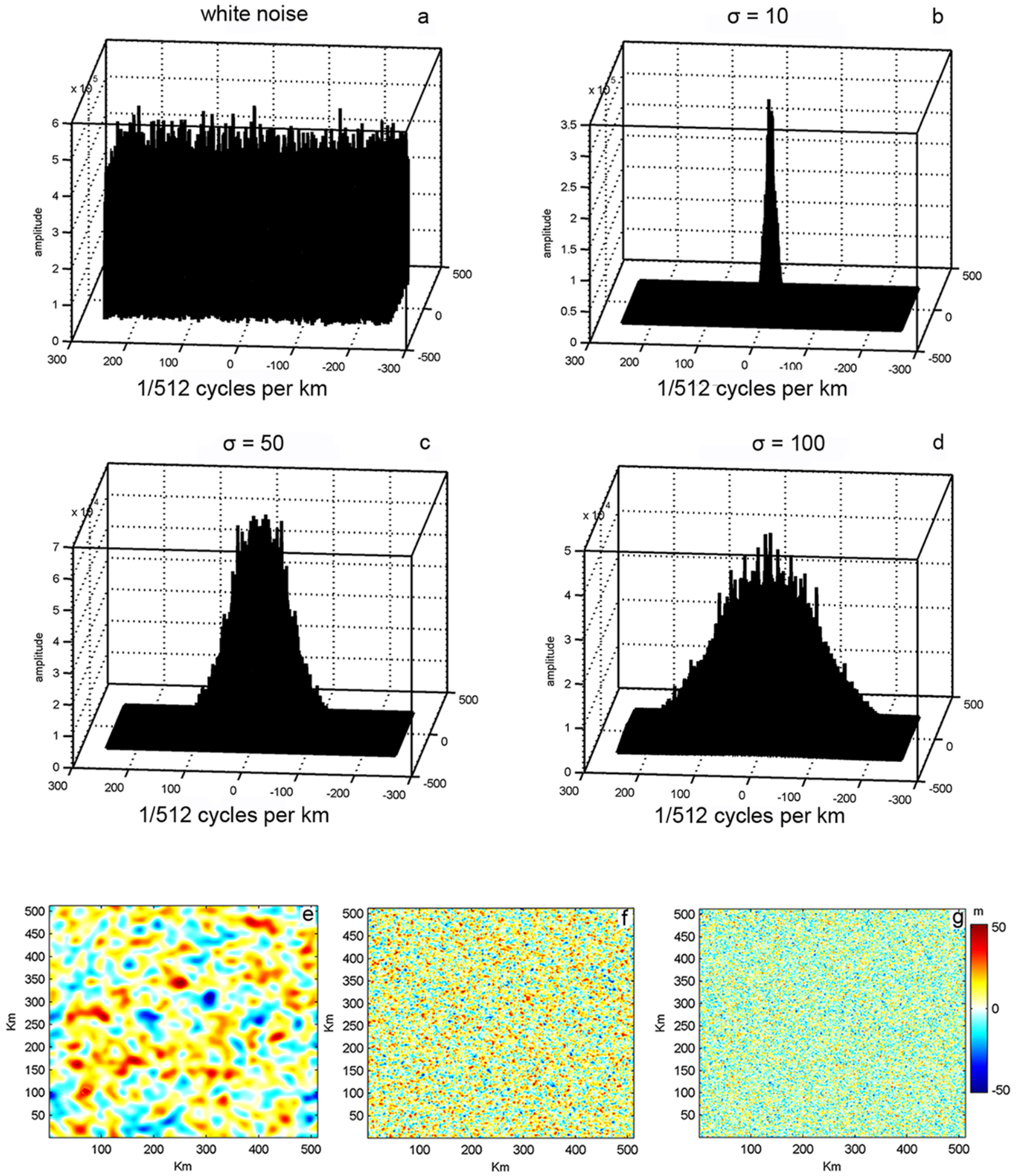

Figure 3. (a-d) noise spectrum for different distributions as labelled. The units of $\sigma$ are as follows: $1 / 512$ cycles per km, and the total power in each noise realization is the same. (e-g) are plots of the lower-, medium- and higher-frequency noise added to the spatial domain of Pine Island Glacier (Fig. 2a). 

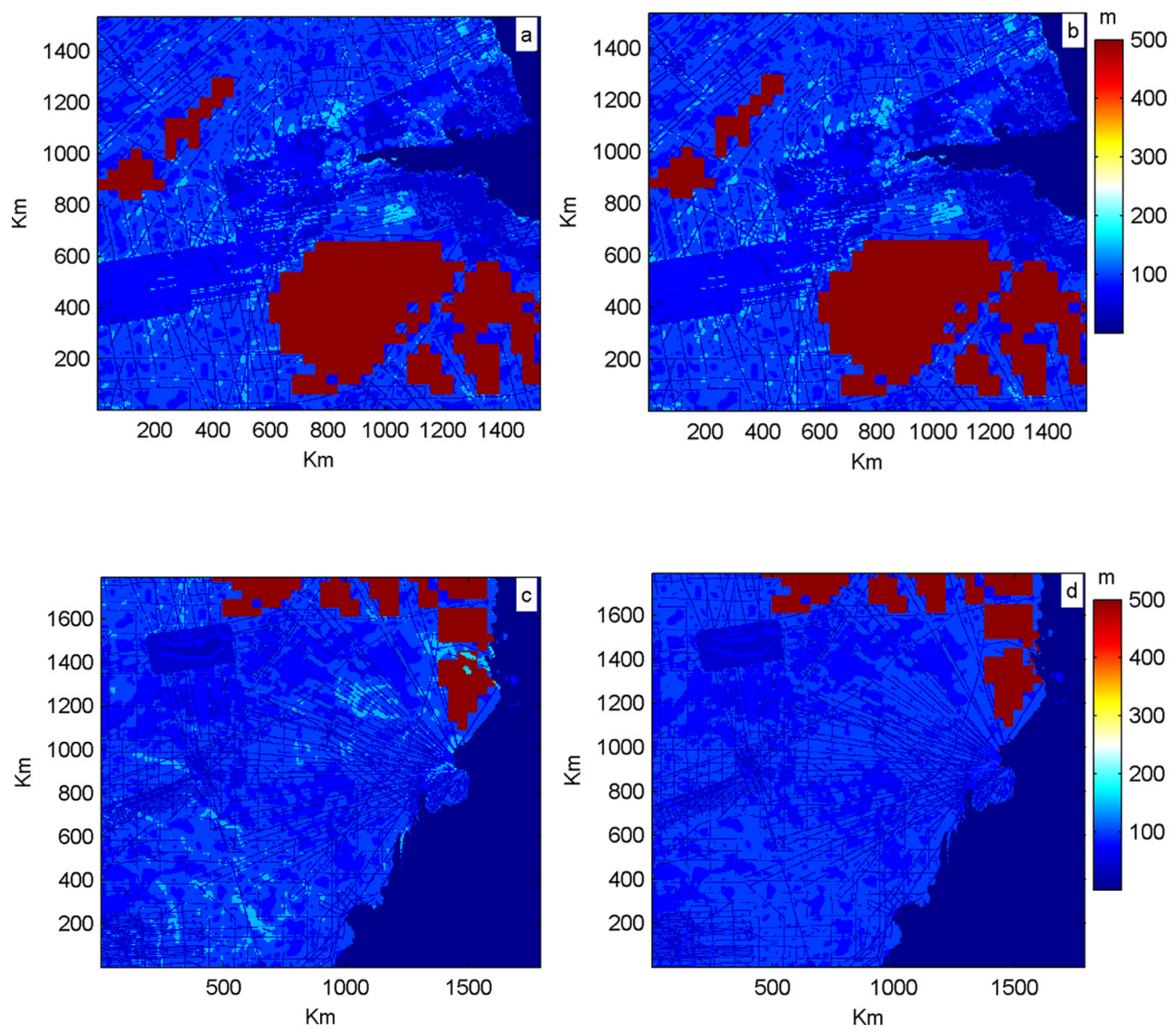

Figure 4. Comparison of uncertainty maps from Bedmap2 (a, c; Fretwell et al., 2013) and the one we use in the model (b,d) for the LambertAmery Basin (a,c) and the Aurora-Basin-Totten-Glacier region (b,d). There are 16 single uncertainty values in Bedmap2; we combined some close values and actually use six uncertainty values. For PIG the uncertainty was uniformly $60 \mathrm{~m}$ across the whole domain (Fig. $3 \mathrm{e}-\mathrm{g}$ ).

the same power. The resulting noise maps are added to the bedrock to provide a set of perturbed geometries. We then use these geometries we made to initialize the ice sheet model.

\subsection{Model}

The ice sheet model we used for the simulation is BISICLES (Cornford et al., 2013). The model uses a vertically integrated treatment of the momentum equation based on L1L2 (Schoof and Hindmarsh, 2010). This physical mechanism is quite suitable for ice shelves and fast-flowing ice streams. It is a high-performance scalable AMR (adaptive mesh refinement) ice sheet model constructed using the Chombo parallel AMR framework, which allows us to use non-uniform, evolving meshes. Here, we implement a mesh with three levels of refinement on top of a $4 \mathrm{~km}$ resolution coarse mesh. The resolution of the vast slow-flowing area is $4 \mathrm{~km}$, while the highest resolution of the fast-flowing area and grounding line is $0.5 \mathrm{~km}$. Meshes are re-generated at each time step. The high-resolution mesh area evolves with changes in the location of the grounding line and the ice streams. In this way, we can capture the dynamics of grounding line and ice streams without wasting computational resources.

We ran 200-year-long prognostic simulations, with perturbation on the bedrock being the only difference between ensemble members. For PIG, each of the 50 simulations required 1 day, while the larger Lambert-Amery domain needed 3 days and the Aurora-Basin-Totten-Glacier region 5 days per simulation with a 16 -core processor. The computing time was bedrock dependent and simulations with higherfrequency noise took longer to achieve convergence.

In addition to the bedrock topography and ice thickness, we need to provide two-dimensional basal traction and enhancement coefficients, a three-dimensional ice temperature, a two-dimensional surface mass balance and a twodimensional sub-shelf melt rate for each run. The temperature and surface mass balance fields are the same for each calculation and are taken from Pattyn (2010) and from Arthern et al. (2006) respectively. The basal traction and enhancement coefficients are calculated using a control method similar to those reported in Joughin et al. $(2009,2010)$, Albrecht and Levermann (2012), MacAyeal (1993) and Morlighem et al. (2010), that is, a gradient-based optimization method that 
seeks to minimize the difference between the modelled velocity and the observed surface velocity (Rignot et al., 2011). We compute basal traction and enhancement coefficients for each perturbed bedrock, since their relationship to the model velocity involves the ice thickness

The sub-ice-shelf melting can be determined indirectly from estimates of ice shelf mass balance (e.g. Rignot et al., 2008; Pritchard et al., 2012). To simplify the parameterization we assume that melt is highest at the grounding line where one might expect deeper and warmer water. We imposed melt as a piecewise linear function of the ice shelf thickness (Cornford et al., 2013; Favier et al., 2014). For Pine Island Glacier, we use a maximum melting rate of $50 \mathrm{~m} \mathrm{yr}^{-1}$ (Jenkins et al., 2010; Joughin et al., 2010; Payne et al., 2007; Jacobs et al., 2011) where ice is thicker than $500 \mathrm{~m}$, linearly decreasing to no melt where ice is thinner than $50 \mathrm{~m}$. For the East Antarctica Lambert-Amery system, the melt rate around the grounding line was determined to be about $30 \mathrm{~m} \mathrm{yr}^{-1}$ (Rignot and Jacobs, 2002; Wen et al., 2010), so we use this value where ice is thicker than $1500 \mathrm{~m}$, linearly decreasing to no melt where ice is thinner than $300 \mathrm{~m}$. For Totten and Moscow ice shelves, temperatures at the deep grounding line are more than $3{ }^{\circ} \mathrm{C}$ above melting point and the ice shelves are considered to be retreating (Rignot et al., 2013). We constrain melting rates such that the grounding line retreats and the whole basin mass loss is comparable to that found by Rignot et al. (2008). Hence we choose a high maximum melt rate of $90 \mathrm{~m} \mathrm{yr}^{-1}$ where ice is thicker than $1500 \mathrm{~m}$, linearly decreasing to no melt where ice is thinner than $300 \mathrm{~m}$. The simple parameterization used here does not allow for basal accretion of marine ice under ice shelves known to occur, for example under parts of the Amery Ice shelf (Fricker et al., 2001). However, while the melt rates are not realistic in all respects, they do allow the model to produce behaviour consistent with observations.

\section{Results}

In this section, we present the model results for Pine Island Glacier, the Lambert-Glacier-Amery-Ice-shelf system and the Aurora-Basin-Totten-Glacier region 200-year simulations. We also run a control experiment where no noise is added to the topography as described in the published bedrock topographic maps.

\subsection{Pine Island Glacier}

The flow regime of PIG changes dramatically over 200 years (Fig. 5). At the start of the simulations, ice flows accelerates along the grounded glacier trunk from a speed of around $100 \mathrm{~m} \mathrm{yr}^{-1}$ to around $2000 \mathrm{~m} \mathrm{yr}^{-1}$, abruptly speeds up to $4000 \mathrm{~m} \mathrm{yr}^{-1}$ as it crosses the grounding line, then remains at a steady speed through a $500 \mathrm{~m}$ thick ice shelf. By the end of the simulations, the grounding line has retreated to the top of the trunk. Ice flows across this new grounding line at around $1500 \mathrm{~m} \mathrm{yr}^{-1}$, accelerates up to $2500 \mathrm{~m} \mathrm{yr}^{-1}$ over the first $100 \mathrm{~km}$ over the ice shelf where the ice is up to $500 \mathrm{~m}$ thick and slopes steeply, then flows into a region of thinning (down to $50 \mathrm{~m}$ ) ice and gently slopes where lateral stresses outweigh the normal and driving stresses so that the flow slows to around $600 \mathrm{~m} \mathrm{yr}^{-1}$ by the time it reaches the calving front.

Mass is lost throughout the simulation (Fig. 6), at a rate equivalent to around $0.1 \mathrm{~mm}$ sea level rise per year during the first years, which rises abruptly to around $0.25 \mathrm{~mm} \mathrm{yr}^{-1}$ after around the 50th year. This rapid change in mass loss rate coincides with the retreat of the grounding line from the submarine ridge it occupied in 1996, with the glacier accelerating as the grounding line retreats into a trough, much as in Favier et al. (2014) and anticipated by Schoof (2007). Note that this change in retreat rate in our calculations is delayed relative to Favier et al. (2014), due to lower sub-shelf melt rates, and is also delayed relative to observations of the grounding line (Park et al., 2013).

The key difference between each of the calculations is the onset of rapid retreat, which varies most for the lowestfrequency noise. Figure 6 shows that once the rapid retreat has begun, the ongoing retreat is essentially the same in each case. For the lowest-frequency noise, the onset of retreat ranges from the 41st year to the 76th year. With mediumfrequency noise, the onset ranges from the 48th year to the 64th year and for the highest-frequency noise, the onset ranges from the 46th year to the 59th year. This variation in onset is related to the height of the ridge underneath the initial grounding line as it crosses the glacier trunk. The mean noise field for the four "early onset" low-frequency simulations, which begin to retreat before the 48th year (one standard deviation before the mean year of onset), has a strong feature: it is negative along the ridge (Fig. 7). Likewise, the mean noise field for the eight "late onset" simulations - that begin to retreat after the 64th year - is positive along the ridge.

In all of our simulations, the grounding line retreats by more than $100 \mathrm{~km}$ (Figs. 2d and 8) during the course of the experiments, but net retreat is sensitive to the bedrock noise and more sensitive to long wavelength noise, largely because of the variation in onset described above. For the experiment with lowest-frequency noise on the bedrock, the most northerly locations of grounding differ by as much as $53 \mathrm{~km}$. Volume above floatation (VAF) loss varies between 17700 and $23000 \mathrm{~km}^{3}$, while the grounding line retreats to uncover between 15300 and $24800 \mathrm{~km}^{2}$. For the mediumfrequency noise, VAF loss ranges from 18600 to $20800 \mathrm{~km}^{3}$ (17000 to $21200 \mathrm{~km}^{2}$ grounding line retreat), and for the highest-frequency noise VAF loss varies between 19200 and $20900 \mathrm{~km}^{3}$ (18 900 to $21100 \mathrm{~km}^{2}$ grounding line retreat). 

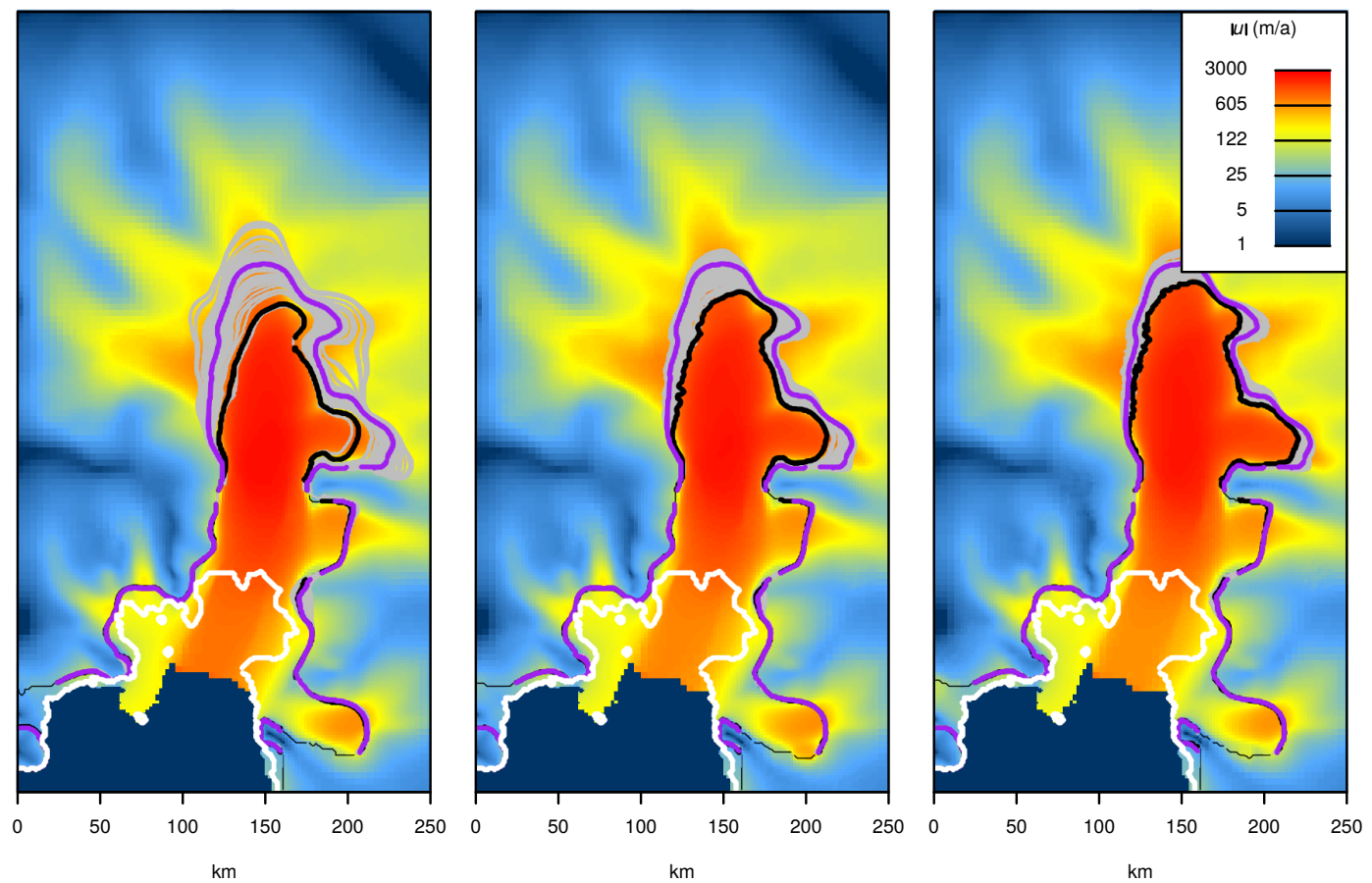

Figure 5. Location of PIG initial (white) and 200-year (grey) grounding lines and ice flow speed in the last simulation year for (left to right) the lower-, medium- and higher-frequency noise experiment. Ice flow speed is plotted for the simulations with the least retreat and corresponds to the black grounding line. The purple contour in each plot is the final grounding line of the noiseless experiment and the white contour is the initial grounding line.

\subsection{Lambert-Glacier-Amery-Ice-shelf}

The glaciers that flow into the Amery Ice shelf change little compared to Pine Island Glacier or the Aurora-Basin-TottenGlacier region described below. VAF increases steadily throughout the simulations, despite the grounding line retreating (Fig. 8) by up to $10 \mathrm{~km}$. The low-, medium- and highfrequency perturbations lead to essentially the same range of VAF increase: between 4400 and $5100 \mathrm{~km}^{3}\left(0.06 \mathrm{~mm} \mathrm{yr}^{-1}\right.$ sea level equivalent) and all of the perturbations result in at least as much as VAF increase as the noiseless simulation (Fig. 9). At the same time, the grounding line retreats to uncover between 2200 and $3900 \mathrm{~km}^{2}$ in the low-frequency case, between 2600 and $3600 \mathrm{~km}^{2}$ in the medium-frequency case and 2300 and $3300 \mathrm{~km}^{2}$ in the high-frequency case, and all result in more net retreat than the noiseless case. Much of the variation is accounted for by an initial advance of the grounding line, which grows in strength as the frequency of noise increases so that the peak of the mean curve tends toward the noiseless curve. Put another way, the addition of lower-frequency noise can act to reduce this advance more than the addition of high-frequency noise.

High-frequency noise acts to slow down retreat in the regions of fast-flowing ice. By computing the change in VAF and grounded area over the regions where ice flows faster than $100 \mathrm{~m} \mathrm{yr}^{-1}$ (Fig. 10), we remove much of the steady upward trend originating in accumulation over the large drainage basin. Figure 10 shows that, while the annual mass loss rate over the fast-flowing region is somewhat less variable in the high-frequency case, the mean rate of grounding line retreat is slower than in the low-frequency case or in the noiseless case. In other words, while the model is less sensitive to the phase of short-wavelength perturbations, it remains sensitive to their amplitude.

\subsection{The Aurora-Basin-Totten-Glacier region}

The outlet glaciers of the Aurora Basin undergo significant retreat during the course of our simulations. The Totten Glacier and Vanderford Glacier grounding lines retreat along the deep submarine trough that fringes Law Dome from its east (Totten) and west (Vanderford) end, nearly meeting at a point around halfway between the two calving fronts (Fig. 11). At the same time, the grounding lines retreat along a broad front stretching for more than $200 \mathrm{~km}$ from Totten Glacier in the west through the Moscow University Ice shelf to the Dalton Ice shelf in the east. Overall, the dynamic changes in the basin outweigh the surface mass balance $\left(229 \mathrm{~km}^{3} \mathrm{yr}^{-1}\right)$, resulting in a total VAF loss of $15000 \mathrm{~km}^{3}$. The rate of VAF loss is larger in the early stages of retreat, with an average value of around $100 \mathrm{~km}^{3} \mathrm{yr}^{-1}$ $\left(0.25 \mathrm{~mm} \mathrm{yr}^{-1}\right.$ sea level equivalent $)$ over the first 100 years and $50 \mathrm{~km}^{3} \mathrm{yr}^{-1}$ subsequently. 

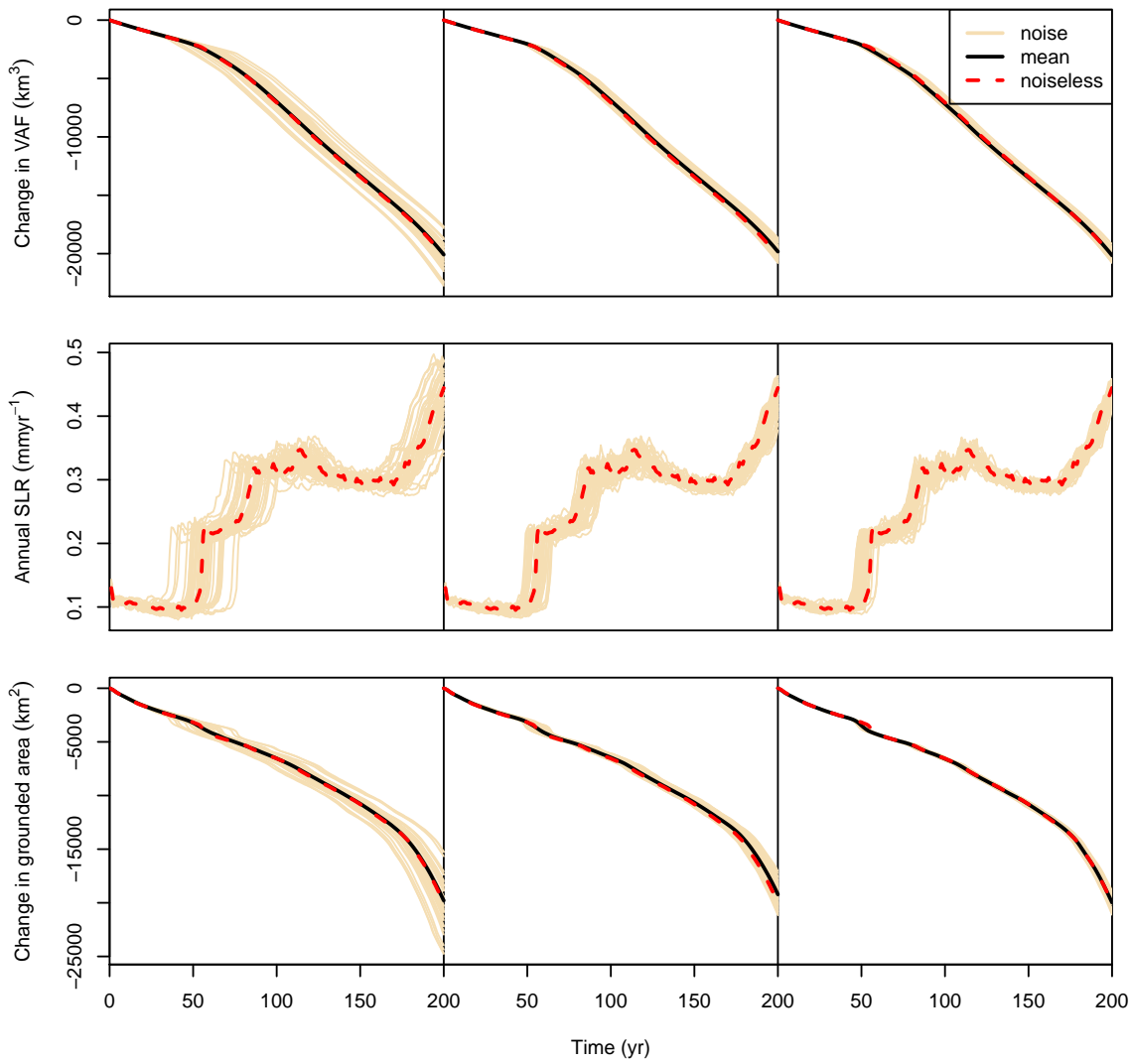

Figure 6. Change in ice volume above floatation (VAF), annual sea level rise (SLR) and change in grounded area for the PIG basin (Fig. 2a, d). The three columns are for experiments with lower- (left), medium- (middle) and higher- (right) frequency noise on the bedrock. Higherfrequency noise leads to less variation than low-frequency noise, while the mean over all of the experiments with noise added is close to the noiseless experiment. Much of the variation is associated with the onset of rapid retreat at around 50 years, evident in the plot of annual SLR.
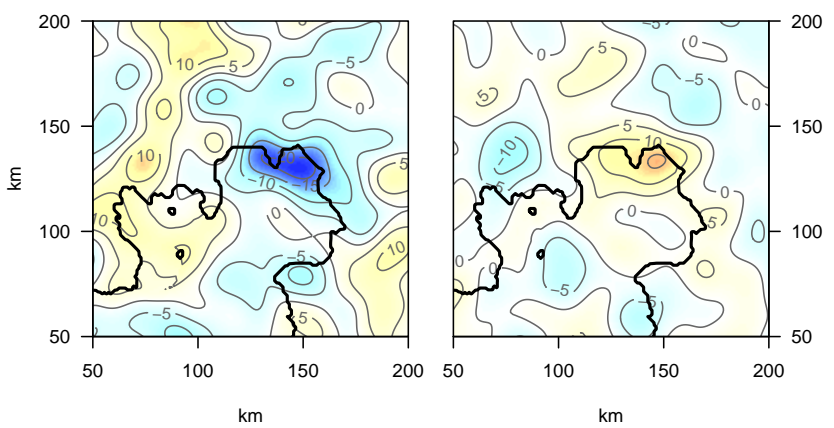

Figure 7. Mean bedrock noise fields for the early- and late-onset low-frequency PIG simulations. The contour interval is $5 \mathrm{~m}$. The mean noise field computed for the four early onset simulations shows a lowering of the ridge where the glacier trunk crosses the initial grounding line (left), while the corresponding field for the eight late-onset simulations shows a rise.

As with Pine Island Glacier, the rate of retreat is more sensitive to the introduction of long-wavelength changes in the bedrock (Fig. 12). The lowest-frequency perturbations lead to between 13200 and $16000 \mathrm{~km}^{3}$ VAF loss and 23000 and

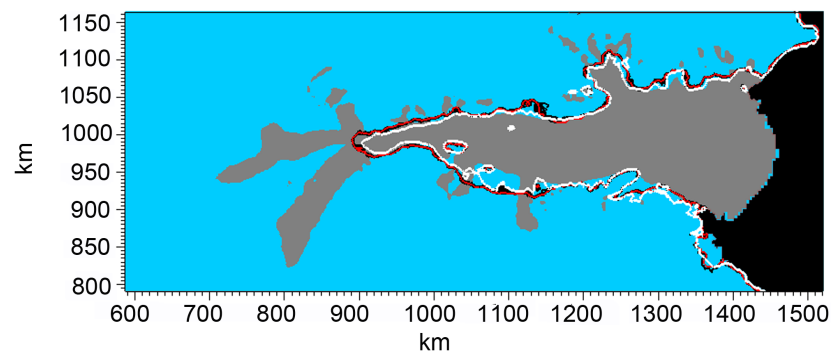

Figure 8. Region where ice velocity $>100 \mathrm{~m} \mathrm{yr}^{-1}$ (grey) for the Lambert-Amery Basin (the boxed region in Fig. 2b). The location of grounding lines (first simulation year in white, last in black) in each of the 50 realizations of the low-frequency noise experiments is shown. The noiseless experiment (red contour) results are close to the other experiments but retreat more in the fast-flowing regions.

$25000 \mathrm{~km}^{2}$ of grounding line retreat, the medium-frequency perturbations to between 14600 and $15300 \mathrm{~km}^{3}$ VAF loss with 23600 to $24900 \mathrm{~km}^{2}$ of grounding line retreat, and the highest-frequency perturbations to between 14600 and $15100 \mathrm{~km}^{3}$ VAF loss with 23800 to $24700 \mathrm{~km}^{2}$ of grounding line retreat. Unlike Pine Island Glacier, there is no delay 

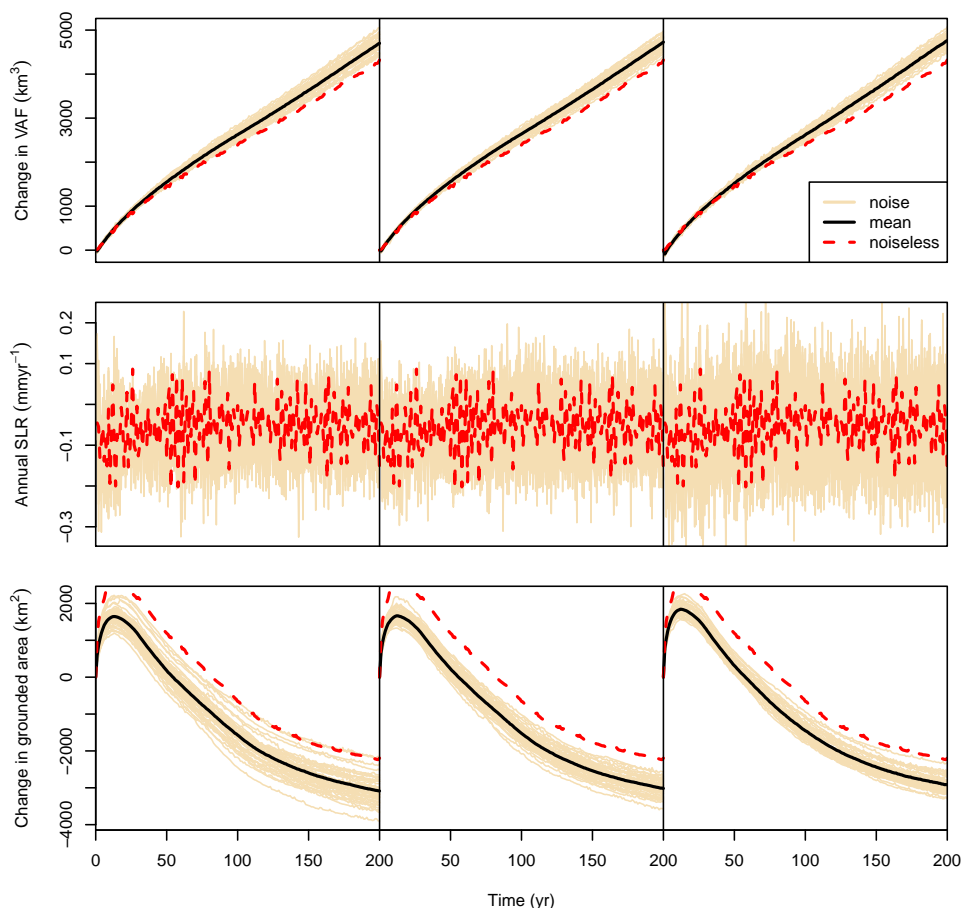

Figure 9. Change in ice volume above floatation (VAF) in the whole Lambert-Amery system (Figs. 1 and $2 b$ ) with the corresponding sea level rise (SLR), equivalent mass loss rate and change in grounded area. The three columns are for experiments with lower- (left), medium(middle) and higher- (right) frequency noise on the bedrock. The ensemble mean VAF is higher than in the noiseless experiment, especially in the results with higher-frequency noise.
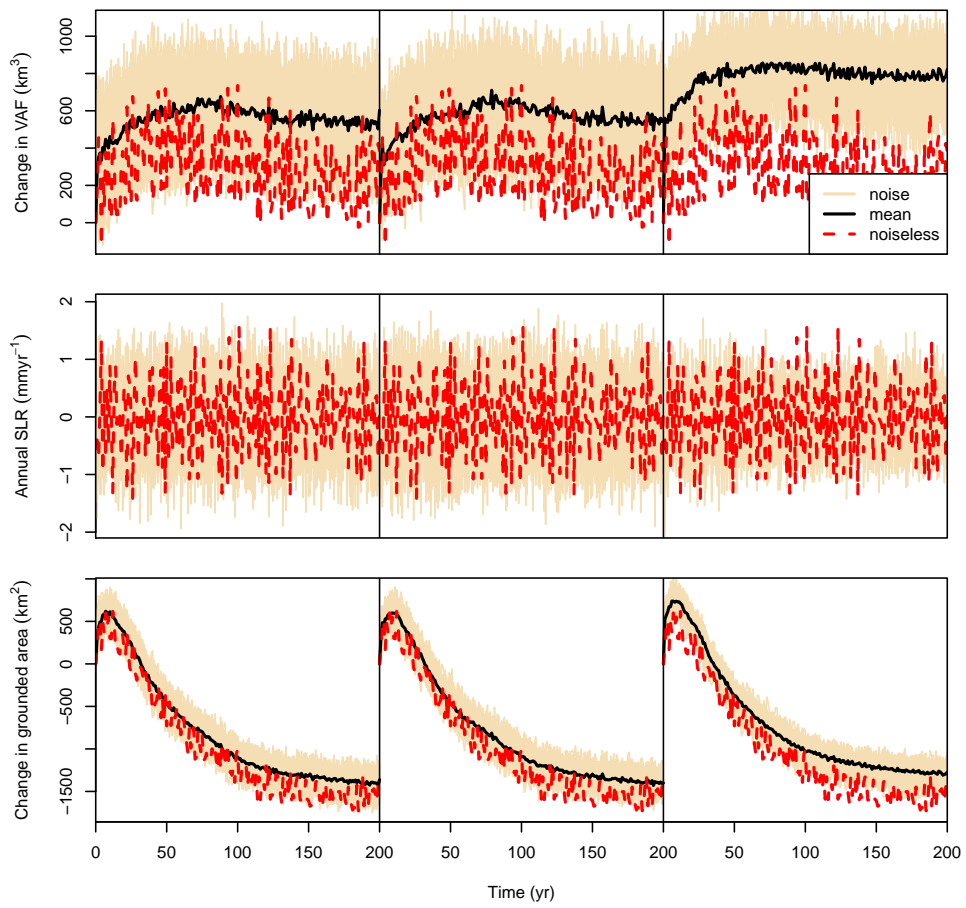

Figure 10. Change in ice volume above floatation (VAF) in the fast-flowing (>100 $\mathrm{m} \mathrm{yr}^{-1}$ ) parts of the Lambert-Glacier-Amery-Ice-shelf system (Figs. 1 and 2b) with the annual sea level rise (SLR) and change in grounded area. The three columns are for experiments with lower(left), medium- (middle) and higher- (right) frequency noise on the bedrock. The addition of higher-frequency noise acts to reduce grounding line retreat, more than low-frequency noise, but results in less variation in mass loss rate. 

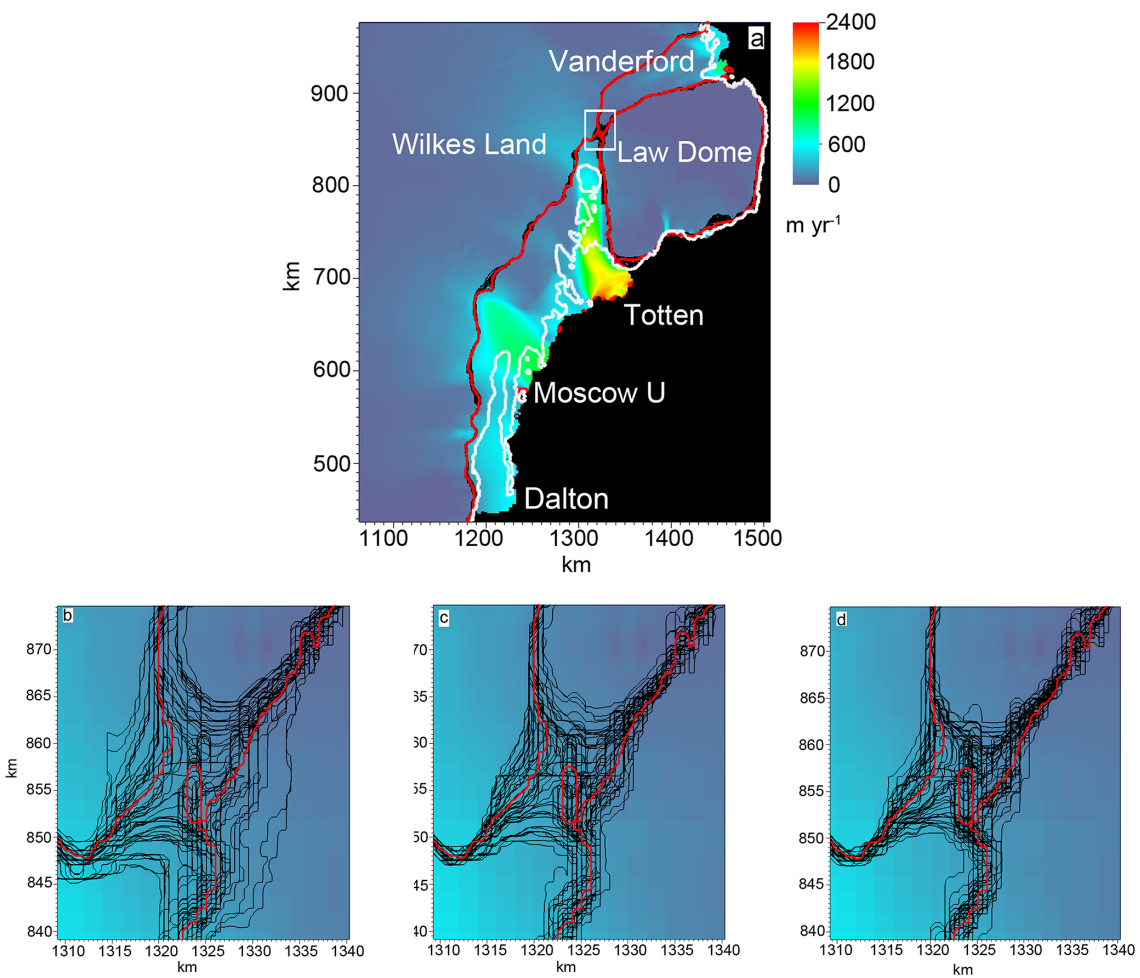

Figure 11. (a) Location of Totten Glacier grounding lines (first simulation year in white, last in black) and the magnitude of ice velocity in the final simulation year. (b-d) Zoom of the boxed area in (a). Location of grounding line in the last simulation year for (left to right) lower-, medium- and higher-frequency noise experiments. The red contour in the three plots is the result of the noiseless experiment.
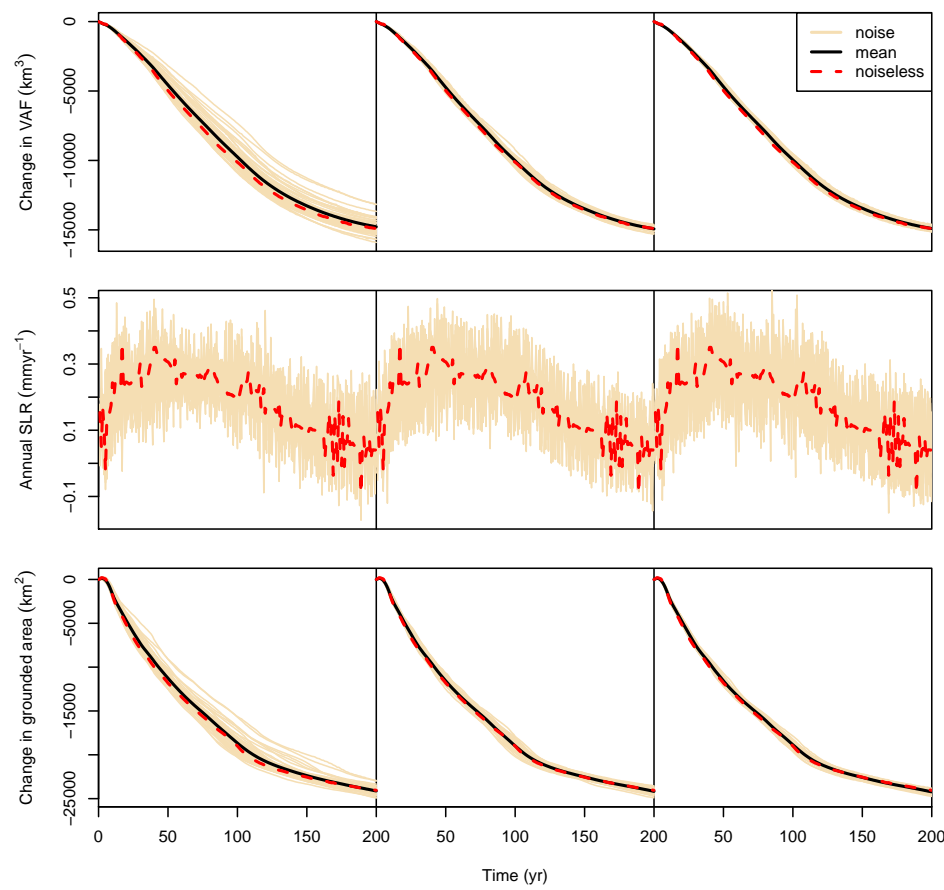

Figure 12. Change in ice volume above floatation (VAF) over the Aurora-Basin-Totten-Glacier region (Figs. 1 and $2 \mathrm{c}$ ), annual sea level rise (SLR) and change in grounded area. The three columns are for experiments with lower- (left), medium- (middle) and higher- (right) frequency noise on the bedrock. The lower-frequency noise results in more variation in the change in both VAF and grounded area than the higher-frequency noise, while the noiseless results are close to the ensemble mean in each case. 
in the onset of retreat, but instead there is variation in the rate at which retreat grows and then shrinks, so we do not attribute the variation to any single bedrock feature.

\section{Discussion and conclusion}

The ice sheet model was subjected to simplistic climatic forcing and was not tuned to present-day discharge, so this study should not be considered a projection of future change but rather a study of the sensitivity to bedrock uncertainty. We have not considered changes in the relative sea level associated with changing mean sea level or local lithospheric loading by the ice sheet. This will be a factor in grounding line location especially in long-term ice sheet mass change (Moore et al., 2013), and the elastic response is known to be measurable when ice shelves disintegrate rapidly (Thomas et al., 2011). The parameterization of sub-shelf melt rates we use is simplistic but does lead to behaviour consistent with the present behaviour of the ice shelves and grounding lines. It is plausible that changes in melt rate could occur if the relatively warm circumpolar Antarctic deep waters start to track closer to the continent (Pritchard et al., 2012), perhaps as a response to changing global temperatures (Moore et al., 2013). Under such conditions the geometry of the sub-shelf cavity and the proximity of the continental shelf break will be important to the ice shelf stability.

The activity of the grounding line differs considerably between the three ice sheet regions we examined. Pine Island Glacier exhibits rapid retreat along a narrow trough. So does Vanderford Glacier, retreating from west to east to almost meet the western edge of Totten Glacier's more slowly retreating grounding line and so isolating Law Dome. On the other hand, we see retreat across a broad front between Totten Glacier and the Dalton Ice shelf and much less retreat in the glaciers that feed the Amery Ice shelf.
The results of our simulations suggest that the phase of low-frequency noise on the bedrock plays a more important role in model projections of ice sheet retreat than the phase of high-frequency noise. This may be in part due to our choice of a low-aspect ratio model, but we note that a full Stokes model also shows a lesser sensitivity to the phase of higherfrequency perturbations, if not to the existence of such perturbations per se (see Appendix). Spatially coherent bedrock irregularities, represented by the lowest-frequency noise examples we show, are more important than the precise details of small-scale surface roughness. In bedrock topography mapping, uncertainties comes primarily from the spacing of radar profiles, but even with arbitrarily closely spaced survey lines, radar mapping cannot refine DEM beyond limits imposed in detecting small-amplitude features by bandwidth and on spatial resolution by diffraction effects. Hence higherfrequency errors in topography would likely remain undetected. However, our results suggest that accurate estimates of elevation over horizontal scales of several kilometres, together with estimates of the amplitude (but not phase) spectrum of shorter-wavelength roughness, are sufficient. Indeed, the most important feature in the Pine Island Glacier simulations was the height of a submarine ridge some $50 \mathrm{~km}$ wide and $20 \mathrm{~km}$ broad - a feature also discussed by Rignot et al. (2014). Lowering or raising this ridge by tens of metres through low-frequency perturbations caused the onset of rapid grounding line retreat to vary by as much as 35 years. 


\section{Appendix A: Sensitivity to bedrock undulations in BISICLES and Elmer/Ice}

BISICLES employs a reduced-complexity stress model, which is only valid for small-aspect ratios and is fast sliding, to reduce computational cost. Since that approximation breaks down as the wavelength of surface or bedrock undulations approaches the ice thickness, it is not clear that the highest-frequency results reported here are valid, and a full Stokes model (which does not assume a low-aspect ratio) might give different results.

We carried out a simple comparison between BISICLES and the full Stokes model Elmer/Ice (Gagliardini et al., 2013) along the lines of the ISMIP-HOM (higher order ice sheet model intercomparison) experiments (Pattyn et al., 2008). The test problems make use of a periodic domain $x \in[0, L]$ with a constant surface slope $s=1000-0.004 x$ and an undulating bedrock $b=s-1000-100 * \sin 2 \pi x / L$.

A uniform basal traction coefficient, $C=250 \mathrm{~Pa} \mathrm{~m}^{-1} \mathrm{yr}$, is imposed together with a uniform rate factor $10^{-16} \mathrm{~Pa}^{-3} \mathrm{a}^{-1}$. These are flow line problems, similar to the ISMIP-HOM Band D experiments but combine basal sliding with bedrock undulation to more closely resemble the experiments in the main body of the paper. By varying the undulation period from $160 \mathrm{~km}$ down to $5 \mathrm{~km}$ we cover a range of wavelengths similar to the main experiments $(512 / 10 \mathrm{~km}$ down to $512 / 100 \mathrm{~km}$ ).

Figure A1 plots the vertically averaged speed for both BISICLES and Elmer/Ice. In this study, BISICLES employs its L1L2* approximation, where vertical shear is included in the effective viscosity but neglected in the mass flux. In that case, the amplitude of variations in the speed decreases with the wavelength of the bedrock undulation. That implies that the solution becomes progressively less sensitive to the phase of bedrock undulations, as seen in the main experiments. The full L1L2 approximation (Schoof and Hindmarsh, 2010) remains somewhat more sensitive to phase at shorter wavelengths.
Elmer/Ice also exhibits less sensitivity to the phase of shorter-wavelength bedrock variations, although its results differ from BISICLES in two ways. First, the horizontally averaged value of the speed begins to decay with wavelength, much as though the basal traction coefficient was growing. Second, there is a rise in speed centred on $x=3 L / 4$ for $L=5 \mathrm{~km}$, in contrast to all the other results, where the maximum speed occurs at $x=L / 4$. However, this second difference is an artifact of the flow line geometry - a similar rise is seen in the flow line (2-D) ISMIP-HOM B results but not in the 3-D ISMIP-HOM A results.

To summarize, both BISICLES and Elmer/Ice are less sensitive to the phase of shorter wavelength fluctuations in the bedrock elevation. That means we would expect both models to exhibit less variability between realizations of the highfrequency red noise considered in the main experiments than between realizations of the low-frequency red noise. On the other hand, BISICLES will tend not to distinguish between high-frequency noise and no noise at all, while Elmer/Ice will produce slower flow across short-wavelength undulations. However, since both models must determine a basal traction coefficient $C(x, y)$ to match observations of velocity in realistic problems, we might expect this difference to be expressed simply through a lower $C(x, y)$ for Elmer/Ice. 

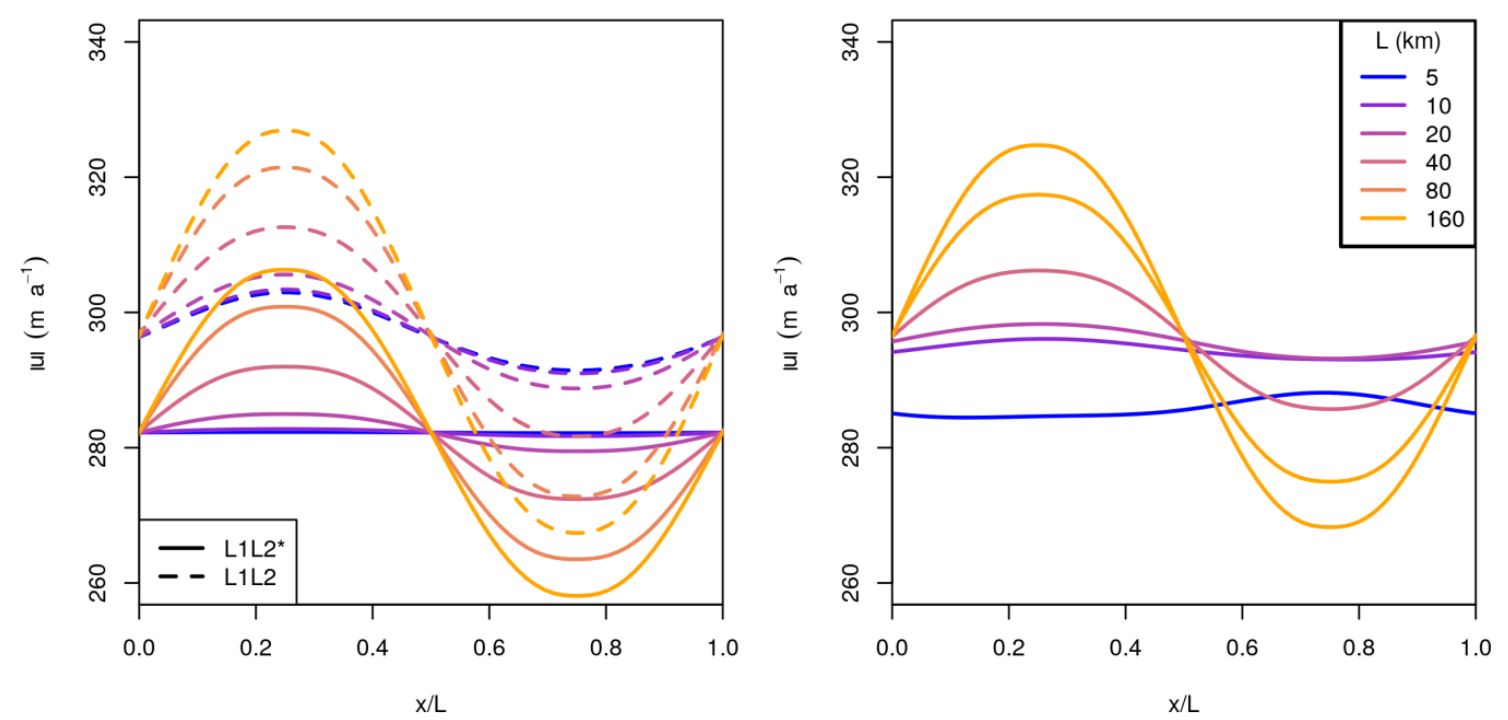

Figure A1. BISICLES and Elmer/Ice vertically averaged speeds for a periodic flow line problem. BISICLES speeds (left, L1L2*) have the same horizontally averaged values for all undulation wavelengths $(L)$, while the amplitude of the oscillation in speed decays with $L$. The same is true for the complete L1L2 approximation, though that still produces appreciable oscillation at all values of $L$. Elmer/Ice (right) shows an intermediate decay in amplitude but also a reduction in the average speed at the smallest $L$. 
Acknowledgements. Funding came from NBRPC 2012CB957702, NSFC No. 41076125, NBRPC 2012CB957704, Fundamental Research Funds for the Central Universities of China 2013NT53, and is publication number 35 of the Nordic Centre of Excellence SVALI, Stability and Variations of Arctic Land Ice, funded by the Nordic Top-level Research Initiative. BISICLES development is led by D. F. Martin at Lawrence Berkeley National Laboratory, California, USA, and S. L. Cornford at the University of Bristol, UK, with financial support provided by the US Department of Energy and the UK Natural Environment Research Council. The geometry of Pine Island Glacier is developed by A. Le Brocq. We thank O. Gagliardini for assistance with Elmer/Ice.

Edited by: O. Gagliardini

\section{References}

Albrecht, T. and Levermann, A.: Fracture field for large-scale ice dynamics, J. Glaciology, 58, 165-176, doi:10.3189/2012JoG11J191, 2012.

Arthern, R. J., Winebrenner, D. P., and Vaughan, D. G.: Antarctic snow accumulation mapped using polarization of $4.3-\mathrm{cm}$ wavelength microwave emission, J. Geophys. Res.-Atmos., 111, D06107, doi:10.1029/2004JD005667, 2006.

Cornford, S. L., Martin, D. F., Graves, D. T., Ranken, D. F., Le Brocq, A. M., Gladstone, R. M., Payne, A. J., Ng, E. G., and Lipscomb, W. H.: Adaptive mesh, finite volume modeling of marine ice sheets, J. Comput. Phys., 232, 529-549, 2013.

De Rydt, J., Gudmundsson, G. H., Corr, H. F. J., and Christoffersen, P.: Surface undulations of Antarctic ice streams tightly controlled by bedrock topography, The Cryosphere, 7, 407-417, doi:10.5194/tc-7-407-2013, 2013.

Durand, G., Gagliardini, O., Favier, L., Zwinger, T., and le Meur, E.: Impact of bedrock description on modeling ice sheet dynamics, Geophys. Res. Lett., 38, L20501, doi:10.1029/2011GL048892, 2011.

Dutrieux, P., Vaughan, D. G., Corr, H. F. J., Jenkins, A., Holland, P. R., Joughin, I., and Fleming, A. H.: Pine Island glacier ice shelf melt distributed at kilometre scales, The Cryosphere, 7, 15431555, doi:10.5194/tc-7-1543-2013, 2013.

Enderlin, E. M., Howat, I. M., and Vieli, A.: High sensitivity of tidewater outlet glacier dynamics to shape, The Cryosphere, 7 , 1007-1015, doi:10.5194/tc-7-1007-2013, 2013.

Favier, L., Gagliardini, O., Durand, G., and Zwinger, T.: A threedimensional full Stokes model of the grounding line dynamics: effect of a pinning point beneath the ice shelf, The Cryosphere, 6, 101-112, doi:10.5194/tc-6-101-2012, 2012.

Fretwell, P., Pritchard, H. D., Vaughan, D. G., Bamber, J. L., Barrand, N. E., Bell, R., Bianchi, C., Bingham, R. G., Blankenship, D. D., Casassa, G., Catania, G., Callens, D., Conway, H., Cook, A. J., Corr, H. F. J., Damaske, D., Damm, V., Ferraccioli, F., Forsberg, R., Fujita, S., Gim, Y., Gogineni, P., Griggs, J. A., Hindmarsh, R. C. A., Holmlund, P., Holt, J. W., Jacobel, R. W., Jenkins, A., Jokat, W., Jordan, T., King, E. C., Kohler, J., Krabill, W., Riger-Kusk, M., Langley, K. A., Leitchenkov, G., Leuschen, C., Luyendyk, B. P., Matsuoka, K., Mouginot, J., Nitsche, F. O., Nogi, Y., Nost, O. A., Popov, S. V., Rignot, E., Rippin, D. M., Rivera, A., Roberts, J., Ross, N., Siegert, M. J., Smith, A. M., Steinhage, D., Studinger, M., Sun, B., Tinto, B. K., Welch, B.
C., Wilson, D., Young, D. A., Xiangbin, C., and Zirizzotti, A.: Bedmaps2: improved ice bed, surface and thickness datasets for Antarctica, The Cryosphere, 7, 375-393, doi:10.5194/tc-7-3752013, 2013.

Gagliardini, O., Zwinger, T., Gillet-Chaulet, F., Durand, G., Favier, L., de Fleurian, B., Greve, R., Malinen, M., Martín, C., Råback, P., Ruokolainen, J., Sacchettini, M., Schäfer, M., Seddik, H., and Thies, J.: Capabilities and performance of Elmer/Ice, a newgeneration ice sheet model, Geosci. Model Dev., 6, 1299-1318, doi:10.5194/gmd-6-1299-2013, 2013.

Gudmundsson, G. H., Krug, J., Durand, G., Favier, L., and Gagliardini, O.: The stability of grounding lines on retrograde slopes, The Cryosphere, 6, 1497-1505, doi:10.5194/tc-6-1497-2012, 2012.

Jacobs, S. S., Jenkins, A., Giulivi, C. F., and Dutrieux, P.: Stronger ocean circulation and increased melting under Pine Island Glacier ice shelf, Nat. Geosci., 4, 519-523, 2011.

Jenkins, A., Dutrieux, P., Jacobs, S. S., McPhail, S. D., Perrett, J. R., Webb, A. T., and White, D.: Observations beneath Pine Island Glacier in West Antarctica and implications for its retreat, Nat. Geosci., 3, 468-472, 2010.

Joughin, I., Tulaczyk, S., Bamber, J. L., Blankenship, D., Holt, J. W., Scambos, T., and Vaughan, D. G.: Basal conditions for Pine Island and Thwaites Glaciers, West Antarctica, determined using satellite and airborne data, J. Glaciol., 55, 245-257, doi:10.3189/002214309788608705, 2009.

Joughin, I., Smith, B. E., and Holland, D. M.: Sensitivity of 21 st century sea level to ocean-induced thinning of Pine Island Glacier, Antarctica, Geophys. Res. Lett., 37, L20502, doi:10.1029/2010GL044819, 2010.

Le Brocq, A. M., Payne, A. J., and Vieli, A.: An improved Antarctic dataset for high resolution numerical ice sheet models (ALBMAP v1), Earth Syst. Sci. Data, 2, 247-260, doi:10.5194/essd-2-247-2010, 2010.

MacAyeal, D. R.: A tutorial on the use of control methods in icesheet modeling, J. Glaciol., 39, 91-98, 1993.

Moore, J. C., Reid, A. P., and Kipfstuhl, J.: Microstructure and electrical properties of marine ice and its relationship to meteoric ice and sea ice, J. Geophys. Res.-Oceans, 99, 5171-5180, doi:10.1029/93JC02832, 1994.

Moore, J. C., Grinsted, A., Zwinger, T., and Jevrejeva, S.: Semiempirical and process-based global sea level projections, Rev. Geophys., 51, 484-522, doi:10.1002/rog.20015, 2013.

Morlighem, M., Rignot, E., Seroussi, H., Larour, E., Ben Dhia, H., and Aubry, D.: Spatial patterns of basal drag inferred using control methods from a full-Stokes and simpler models for Pine Island Glacier, West Antarctica, Geophys. Res. Lett., 37, L14502, doi:10.1029/2010GL043853, 2010.

Pattyn, F., Perichon, L., Aschwanden, A., Breuer, B., de Smedt, B., Gagliardini, O., Gudmundsson, G. H., Hindmarsh, R. C. A., Hubbard, A., Johnson, J. V., Kleiner, T., Konovalov, Y., Martin, C., Payne, A. J., Pollard, D., Price, S., Rückamp, M., Saito, F., Souc(ek, O., Sugiyama, S., and Zwinger, T.: Benchmark experiments for higher-order and full-Stokes ice sheet models (ISMIPHOM), The Cryosphere, 2, 95-108, doi:10.5194/tc-2-95-2008, 2008.

Pattyn, F.: Antarctic subglacial conditions inferred from a hybrid ice sheet/ice stream model, Earth Planet. Sc. Lett., 295, 451-461, 2010. 
Park, J. W., Gourmelen, N., Shepherd, A., Kim, S. W., Vaughan, D. G., and Wingham, D. J.: Sustained retreat of the Pine Island Glacier, Geophys. Res. Lett., 40, 2137-2142, 2013.

Payne, A. J., Holland, P. R., Shepherd, A. P., Rutt, I. C., Jenkins, A., and Joughin, I.: Numerical modeling of ocean-ice interactions under Pine Island Bay's ice shelf, J. Geophys. Res.-Oceans, 112, C10019, doi:10.1029/2006JC003733, 2007.

Pozdeev, V. S. and Kurinin, R. G.: New data on ice sheet morphology, bedrock and bottom relief in the Southern Weddell Sea Basin, West Antarctica, Antarktika, Doklady Komissii, 26, 6671, 1987.

Pritchard, H. D., Ligtenberg, S. R. M., Fricker, H. A., Vaughan, D. G., van den Broeke, M. R., and Padman, L.: Antarctic ice-sheet loss driven by basal melting of ice shelves, Nature, 484, 502-505, 2012.

Rignot, E. and Jacobs, S. S.: Rapid Bottom Melting Widespread near Antarctic Ice Sheet Grounding Lines, Science, 296, 2020 2023, doi:10.1126/science.1070942, 2002.

Rignot, E. and Thomas, R. H.: Mass Balance of Polar Ice Sheets, Science, 297, 1502-1506, doi:10.1126/science.1073888, 2002.

Rignot, E.: Changes in West Antarctic ice stream dynamics observed with ALOS PALSAR data, Geophys. Res. Lett., 35, L12505, doi:10.1029/2008GL033365, 2008.

Rignot, E., Bamber, J. L., van den Broeke, M. R., Davis, C., Li, Y., van de Berg, W. J., and van Meijgaard, E.: Recent Antarctic ice mass loss from radar interferometry and regional climate modelling, Nat. Geosci., 1, 106-110, 2008.

Rignot, E., Mouginot, J., and Scheuchl, B.: Ice Flow of the Antarctic Ice Sheet, Science, 333, 1427-1430, doi:10.1126/science.1208336, 2011.

Rignot, E., Jacobs, S., Mouginot, J., and Scheuchl, B.: IceShelf Melting Around Antarctica, Science, 341, 266-270, doi:10.1126/science.1235798, 2013.

Rignot, E., Mouginot, J., Morlighem, M., Seroussi, H., and Scheuchl, B.: Widespread, rapid grounding line retreat of Pine Island, Thwaites, Smith and Kohler glaciers, West Antarctica from 1992 to 2011: Grounding line retreat West Antarctica, Geophys. Res. Lett., doi:10.1002/2014GL060140, 2014.

Robin, G. D. Q., Evans, S., and Bailey, J. T.: Interpretation of Radio Echo Sounding in Polar Ice Sheets, Philos. T. R. Soc. Lond., 265, 437-505, 10.2307/73767, 1969.

Sasgen, I., Konrad, H., Ivins, E. R., Van den Broeke, M. R., Bamber, J. L., Martinec, Z., and Klemann, V.: Antarctic ice-mass balance 2003 to 2012: regional reanalysis of GRACE satellite gravimetry measurements with improved estimate of glacial-isostatic adjustment based on GPS uplift rates, The Cryosphere, 7, 1499-1512, doi:10.5194/tc-7-1499-2013, 2013.
Schoof, C.: Ice sheet grounding line dynamics: Steady states, stability, and hysteresis, J. Geophys. Res.-Earth, 112, F03S28, doi:10.1029/2006JF000664, 2007.

Schoof, C. and Hindmarsh, R. C. A.: Thin-Film Flows with Wall Slip: An Asymptotic Analysis of Higher Order Glacier Flow Models, Q. J. Mech. Appl. Math., 63, 73-114, doi:10.1093/qjmam/hbp025, 2010.

Shepherd, A. and Wingham, D.: Recent Sea-Level Contributions of the Antarctic and Greenland Ice Sheets, Science, 315, 15291532, doi:10.1126/science.1136776, 2007.

Shepherd, A., Ivins, E. R., A, G., Barletta, V. R., Bentley, M. J., Bettadpur, S., Briggs, K. H., Bromwich, D. H., Forsberg, R., Galin, N., Horwath, M., Jacobs, S., Joughin, I., King, M. A., Lenaerts, J. T. M., Li, J., Ligtenberg, S. R. M., Luckman, A., Luthcke, S. B., McMillan, M., Meister, R., Milne, G., Mouginot, J., Muir, A., Nicolas, J. P., Paden, J., Payne, A. J., Pritchard, H., Rignot, E., Rott, H., Sørensen, L. S., Scambos, T. A., Scheuchl, B., Schrama, E. J. O., Smith, B., Sundal, A. V., van Angelen, J. H., van de Berg, W. J., van den Broeke, M. R., Vaughan, D. G., Velicogna, I., Wahr, J., Whitehouse, P. L., Wingham, D. J., Yi, D., Young, D., and Zwally, H. J.: A Reconciled Estimate of Ice-Sheet Mass Balance, Science, 338, 1183-1189, doi:10.1126/science.1228102, 2012.

Thomas, I. D., King, M. A., Bentley, M. J., Whitehouse, P. L., Penna, N. T., Williams, S. D. P., Riva, R. E. M., Lavallee, D. A., Clarke, P. J., King, E. C., Hindmarsh, R. C. A., and Koivula, H.: Widespread low rates of Antarctic glacial isostatic adjustment revealed by GPS observations, Geophys. Res. Lett., 38, L22302, doi:10.1029/2011GL049277, 2011.

Velicogna, I. and Wahr, J.: Measurements of Time-Variable Gravity Show Mass Loss in Antarctica, Science, 311, 1754-1756, doi:10.1126/science.1123785, 2006.

Wingham, D. J., Ridout, A. J., Scharroo, R., Arthern, R. J., and Shum, C. K.: Antarctic Elevation Change from 1992 to 1996, Science, 282, 456-458, doi:10.1126/science.282.5388.456, 1998.

Wingham, D. J., Shepherd, A., Muir, A., and Marshall, G. J.: Mass balance of the Antarctic ice sheet, Philos. T. R. Soc. A, 364 , 1627-1635, doi:10.1098/rsta.2006.1792, 2006.

Zwally, H. J., Giovinetto, M. B., Li, J., Cornejo, H. G., Beckley, M. A., Brenner, A. C., Saba, J. L., and Yi, D.: Mass changes of the Greenland and Antarctic ice sheets and shelves and contributions to sea-level rise: 1992\&\#8211;2002, J. Glaciol., 51, 509527, doi:10.3189/172756505781829007, 2005. 